Research Paper

\title{
Proteomic identification of the lactate dehydrogenase $A$ in a radioresistant prostate cancer xenograft mouse model for improving radiotherapy
}

\author{
Jingli Hao ${ }^{1,2}$, Peter Graham ${ }^{1,2}$, Lei Chang ${ }^{1,2,3}$, Jie Ni, ${ }^{1,2}$, Valerie Wasinger ${ }^{4,5}$, Julia \\ Beretov $^{1,2,6}$, Junli Deng ${ }^{1,2}$, Wei Duan? ${ }^{7}$ Joseph Bucci ${ }^{1,2}$, David Malouf ${ }^{8}$, David \\ Gillatt ${ }^{8,9}$, Yong $\mathbf{L i}^{1,2}$ \\ ${ }^{1}$ Cancer Care Centre, St George Hospital, Kogarah, NSW 2217, Australia \\ ${ }^{2}$ St George and Sutherland Clinical School, Faculty of Medicine, University of New South Wales, Sydney, NSW 2052, Australia \\ ${ }^{3}$ Department of Obstetrics and Gynecology, The First Affiliated Hospital of Zhengzhou University, Zhengzhou, Henan 450052, \\ China \\ ${ }^{4}$ Bioanalytical Mass Spectrometry Facility, Mark Wainwright Analytical Centre, Sydney, NSW 2052, Australia \\ ${ }^{5}$ School of Medical Sciences, Sydney, NSW 2052, Australia \\ ${ }^{6}$ SEALS, Anatomical Pathology, St George Hospital, Kogarah, NSW 2217, Australia \\ ${ }^{7}$ School of Medicine, Deakin University, Waurn Ponds, Victoria 3217, Australia \\ ${ }^{8}$ Department of Urology, St George Hospital, Kogarah, NSW 2217, Australia \\ ${ }^{9}$ Australian School of Advanced Medicine, Macquarie University, Sydney, NSW 2019, Australia \\ Correspondence to: Yong Li, email: y.li@unsw.edu.au \\ Jingli Hao, email: jingli.hao@hotmail.com
}

Keywords: prostate cancer, proteomics, glycolysis, LDHA, radiotherapy

Received: September 02, $2016 \quad$ Accepted: September 15, 2016

Published: September 30, 2016

\section{ABSTRACT}

Radioresistance is a major challenge for prostate cancer (CaP) metastasis and recurrence after radiotherapy. This study aimed to identify potential protein markers and signaling pathways associated with radioresistance using a PC-3 radioresistant (RR) subcutaneous xenograft mouse model and verify the radiosensitization effect from a selected potential candidate. PC-3RR and PC-3 xenograft tumors were established and differential protein expression profiles from two groups of xenografts were analyzed using liquid chromatography tandem-mass spectrometry. One selected glycolysis marker, lactate dehydrogenase A (LDHA) was validated, and further investigated for its role in CaP radioresistance. We found that $\mathbf{3 7 8}$ proteins and 51 pathways were significantly differentially expressed between PC-3RR and PC-3 xenograft tumors, and that the glycolysis pathway is closely linked with CaP radioresistance. In addition, we also demonstrated that knock down of LDHA with siRNA or inhibition of LDHA activity with a LDHA specific inhibitor (FX-11), could sensitize PC-3RR cells to radiotherapy with reduced epithelial-mesenchymal transition, hypoxia, DNA repair ability and autophagy, as well as increased DNA double strand breaks and apoptosis. In summary, we identified a list of potential RR protein markers and important signaling pathways from a PC-3RR xenograft mouse model, and demonstrate that targeting LDHA combined with radiotherapy could increase radiosensitivity in RR CaP cells, suggesting that LDHA is an ideal therapeutic target to develop combination therapy for overcoming CaP radioresistance. 


\section{INTRODUCTION}

Radiotherapy (RT) is a standard treatment option for both organ-confined and regionally advanced prostate cancer $(\mathrm{CaP})$. Despite more and more effective advances in radiation delivery procedures, about $50 \% \mathrm{CaP}$ patients undergoing RT suffer from relapse (recurrence) within 5 years of treatment [1]. Radioresistance (the failure to RT) is a major challenge for the current $\mathrm{CaP}$ $\mathrm{RT}$. The mechanisms of cancer radioresistance are very complicated and affected by many factors, which severely affect radiation efficacy. One reason for these failures following RT is due to the intrinsic radioresistance of a subpopulation of clones within the tumor [2] while another reason could be the acquired radioresistance during RT [3, 4]. Current markers used in clinics are not sufficient to separate radiosensitive $\mathrm{CaP}$ from radioresistant (RR) $\mathrm{CaP}$ to predict its radiation response and develop a personalized treatment. Therefore, it is important to identify therapeutic targets associated with $\mathrm{CaP}$ radioresistance and develop novel adjuvant treatments to cure the disease. If the potential targets for radiosensitization are identified and further validated, it will achieve a more favorable therapeutic ratio in clinics.

Due to considerable genetic, behavioral, and environmental heterogeneity, it is very difficult to discover and verify cancer biomarkers directly in human samples. Mouse model can be conducted under stringent genetic and environmental control for biomarker discovery and verification $[5,6]$. The mouse model derived biomarkers, after validation in human patient' sera, have been applied to develop multifactorial predictors of survival of castration-resistant CaP (CRPC) [7]. Therefore, the application of mouse models is highly promising for expanding our understanding of radioresistance, biomarker identification, and thereby moving closer to enhancing the prediction of radiosensitivity, and improving the treatment of RR cancer patients.

Using a low dose fractionated radiation treatment, we have recently developed CaP-RR cell lines with increased colony formation, invasion ability, sphere formation capability and enhanced epithelial-mesenchymal transition (EMT) and cancer stem cell (CSC) phenotypes and the activation of the $\mathrm{PI} 3 \mathrm{~K} / \mathrm{Akt} / \mathrm{mTOR}$ signaling pathway [8]. In the current study, one of the CaP-RR cell lines-PC-3RR, which was developed mimicking clinical conditions and representing the source of $\mathrm{CaP}$ recurrence after RT, was implanted subcutaneously in non-obese diabetic/severe combined immunodeficiency (NOD/SCID) mice and allowed to develop xenograft tumors in vivo. Comparing protein profiles of the RR tumor xenografts to the radiosensitive tumor xenografts provides an ideal model to investigate biomarkers and signaling pathways associated with $\mathrm{CaP}$ radioresistance.

In this study, we firstly identified differentially expressed proteins (DEPs) and a panel of pathways associated with $\mathrm{CaP}$ radioresistance from $\mathrm{PC}-3$ and $\mathrm{PC}$ 3RR xenografts using liquid chromatography tandemmass spectrometry (LC-MS/MS) technique and Ingenuity Pathway Analysis (IPA). In addition, a glycolysis marker lactate dehydrogenase A (LDHA), which is among the significant DEPs and sits in one of the most significantly deregulated pathways in radioresistance, was further validated in CaP-RR cell lines and PC-3RR xenograft tumors. LDHA is a main metabolic enzyme for lactate production which is a terminal product from glycolysis and plays an essential role in the glycolysis. We demonstrated that silencing of LDHA using the small interfering RNA (siRNA) or inhibition of LDHA with a small molecular inhibitor (FX-11) combined with RT reversed radioresistance in PC-3RR cells. Our findings have significant implications for developing novel therapies to overcome radioresistance and improve current CaP RT.

\section{RESULTS}

\section{Establishment of the PC-3 and PC-3RR s.c xenograft models}

PC-3 and PC-3RR subcutaneous (s.c) xenograft tumors were established and allowed to grow up to 7 weeks. The growth rate of PC-3 and PC-3RR tumors at all time points and their tumor sizes at the end of the experiment did not show statistical difference $(p>0.05)$ (Figure 1A and 1B). The tumor xenografts from these mice were collected at the end of experiment for immunohistochemistry (IHC) staining as well as for proteomics analysis.

\section{Histological and IHC differences observed between PC-3 and PC-3RR s.c xenograft tumors}

The histology (H\&E staining) results from two animal xenografts indicate that the density of blood vessels in the PC-3RR tumors (as shown by the arrows) was increased compared to the PC-3 tumors (Figure 1C), suggesting the existence of higher levels of angiogenesis in PC-3RR model. The increased vasculature (angiogenesis) was further confirmed by CD31 and VEGFR2 staining (Figure 1C). Hypoxia marker HIF-1 $\alpha$ was also found to be increased in the PC-3RR tumors compared to the PC-3 tumors (Figure $1 \mathrm{C}$ ). In addition, we also found enhanced EMT (increased N-Cadherin and reduced E-Cadherin) and CSC phenotypes (CD44 and Oct-4) in the PC-3RR xenograft tumors compared to the PC-3 control tumor (Figure 1C), which is consistent with our previous in vitro studies with CaP-RR cell lines [8]. The immunostaining intensity of IHC for CD31, VEGFR2, HIF-1 $\alpha$, EMT and CSC markers is summarized in Supplementary Table S1. These results suggest that PC-3RR xenograft tumor model retains phenotypic features of in vitro PC-3RR 
cells [8] and is suitable for proteomic analysis of CaP-RR biomarkers.

\section{Protein identification and quantification in PC-3 and PC-3RR xenograft tumors}

To investigate the DEPs in PC-3 and PC-3RR xenograft tumors, multivariate analysis of protein expression was performed using principal components analysis (PCA), according to abundance variation. It was demonstrated that PC-3 tumors clustered (the pink spotsleft side) while PC-3RR tumors clustered (the blue spotsright side) (Figure 2A). This demonstrates that $49 \%$ of the differences observed between these phenotypes can be attributed to the PC-3 xenografts vs PC-3RR xenografts. ANOVA $p$-values were used to determine DEPs. There were 378 proteins identified to be significantly differentially expressed between PC-3 and PC-3RR tumor xenograft samples $(p<0.05)$ (Supplementary Table S2).

\section{Network analysis and top canonical pathway terms in PC-3 and PC-3RR xenograft tumors}

IPA was used to reveal the signaling networks and metabolic pathways enriched in the DEPs. Data from all DEPs were submitted in Ingenuity software for pathway analysis. Fifty one pathway terms that are significantly deregulated in PC-3RR tumours were identified (Supplementary Table S3). Thirty-seven of those are associated with $\mathrm{CaP}$ (Supplementary Table S3). The important pathways related with $\mathrm{CaP}$ include Glycolysis Metabolism, VEGF, and Epithelial Adherens Junction signaling pathways. Using IPA, the DEPs were clustered based on locations and functions performed (Figure 2B, 2C). Of the 378 DEPs identified from PC-3 and PC-3RR paired xenografts, 271 proteins were mapped to pathways which were overly enriched in RR samples. The origin of these enriched pathway proteins includes 148 cytoplasm (54.6\%) and 37 nucleus (13.7\%), 37
A

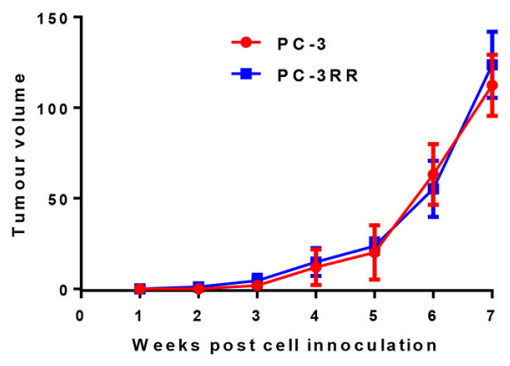

C

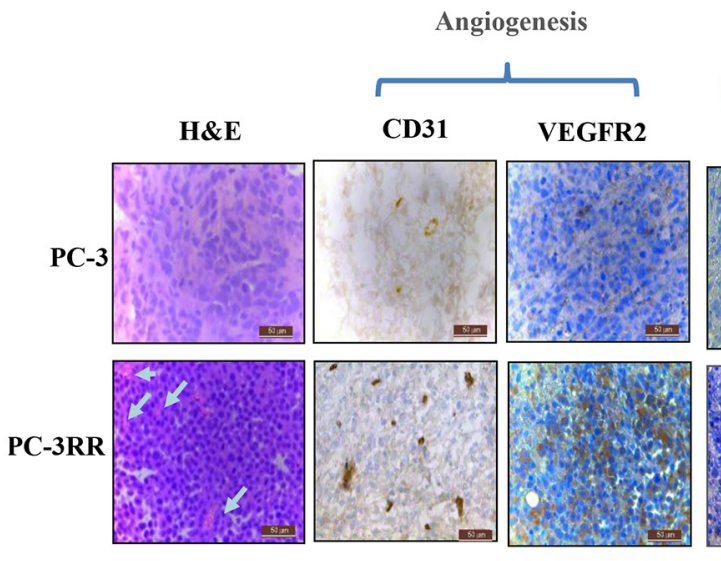

B
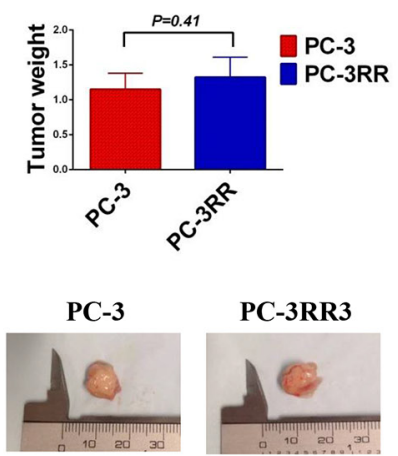

PC-3RR3
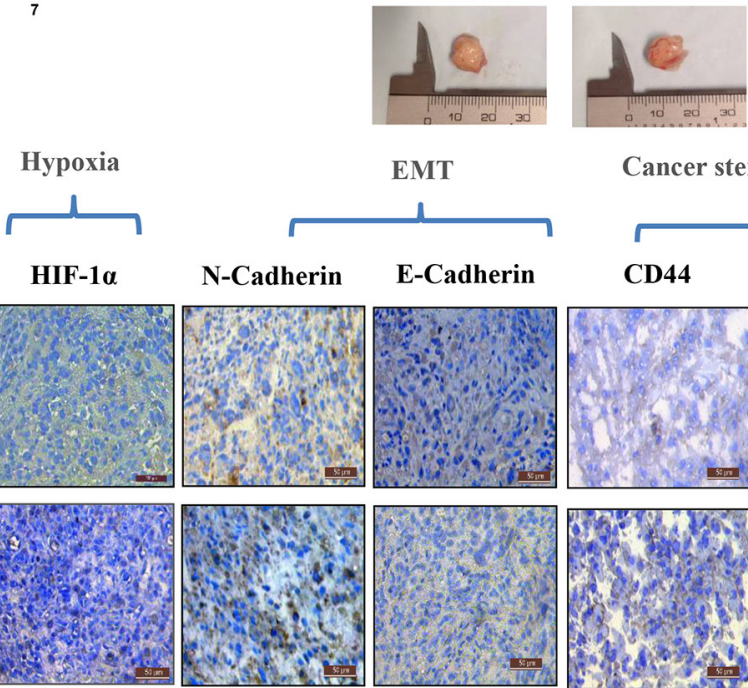

N-Cadherin E-Cadherin

Cancer stem cell markers

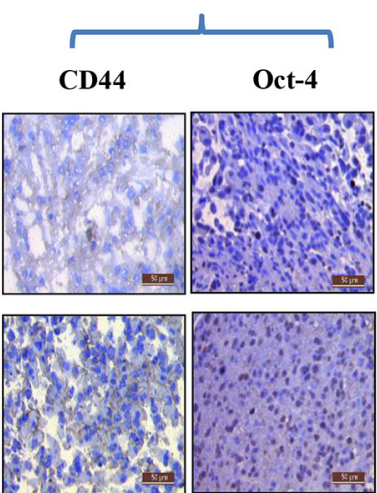

Figure 1: Growth of PC-3 and PC-3RR tumors in vivo and IHC for vasculature, hypoxia, EMT and CSC markers in animal xenografts. A. The growth rates of PC-3 and PC-3RR s.c tumors. PC-3 and PC-3RR tumors were allowed to grow for 7 weeks. No significant difference was found for tumor growth between two models at all time points $(p>0.05)$. B. At the end of the experiment, the tumor weights from PC-3 and PC-3RR groups of mice did not show significant difference ( $\mathrm{n}=5, \mathrm{mean} \pm \mathrm{SD}, p>0.05)$. Representative images are shown for the tumor sizes in the two groups of mice. C. Histology and IHC evaluation of PC-3 and PC-3RR tumors. The cellular patterns and vasculatures (indicated by the white arrows) are shown in the H\&E staining. CD31, VEGFR2, HIF-1 $\alpha$, N-Cadherin, CD44 and Oct-4 were upregulated in PC-3RR xenografts while E-Cadherin was downregulated in PC-3RR xenografts. Brown indicates positive staining while blue indicates nuclei. Magnification $\mathrm{x} 400$ in all images. Scale bar $=50 \mu \mathrm{m}$ 
plasma membrane (13.7\%) and 23 extracellular space (8.5\%) (Figure 2B). The main cellular molecular functions of these DEPs include 73 enzymes (26.9\%), 21 kinase/ peptidase/ phosphatases (7.7\%), 21 transporters (7.7\%), 9 transcription regulators $(3.3 \%)$, and 6 translation regulators $(2.2 \%)$ (Figure $2 \mathrm{C}$ ). These results indicate the DEPs identified have multiple functional roles in $\mathrm{CaP}$ radioresistance.

\section{Examination of glycolysis pathway proteins in PC-3 and PC-3RR xenograft tumors}

As glycolysis pathway was identified as an important signaling pathway from the proteomic analysis, we further validated the key proteins of this pathway in PC-3 and PC3RR xenograft tumors by IHC and Western blot. We found that the expression of the key glycolysis markers (GLUT$1, \mathrm{PKM} 1 / 2$ and LDHA) were significantly increased in PC-3RR xenografts compared with PC-3 xenografts and no positive staining for the detected markers was observed in the control sections (Figure 3A). The immunostaining intensity of glycolysis markers from IHC is summarized in Supplementary Table S1. The IHC results from PC-3 and PC-3RR xenograft tumors were confirmed by Western blot (Figure 3B, 3C). These results further support that the glycolysis pathway is associated with $\mathrm{CaP}$ radioresistance.

\section{Expression of LDHA in CaP RR cell lines and PC-3RR xenograft tumors}

To further study the importance of glycolysis in $\mathrm{CaP}$ radioresistance, LDHA was chosen as a candidate for the functional validation. We demonstrated that increased expression of LDHA protein was found in CaP-RR (PC3RR, DU145RR and LNCaPRR) cells compared with CaP control cells (Figure 4A). The quantification of LDHA Western blot results from $\mathrm{CaP}$ and $\mathrm{CaP}-\mathrm{RR}$ cell lines was presented in Figure 4B. The results were normalized by the level of $\beta$-actin and expressed as mean $\pm \mathrm{SD}(\mathrm{n}=3)$ $(p<0.05)$. In addition, we also demonstrated the up-

A

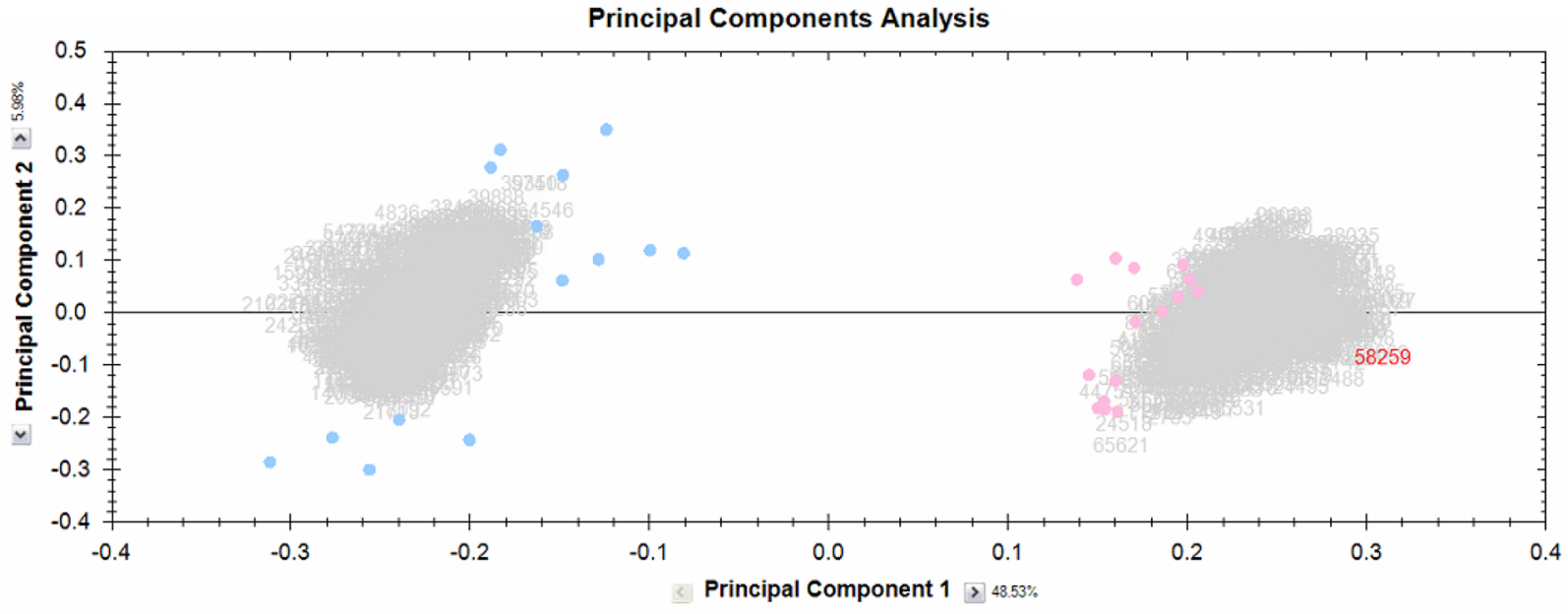

B

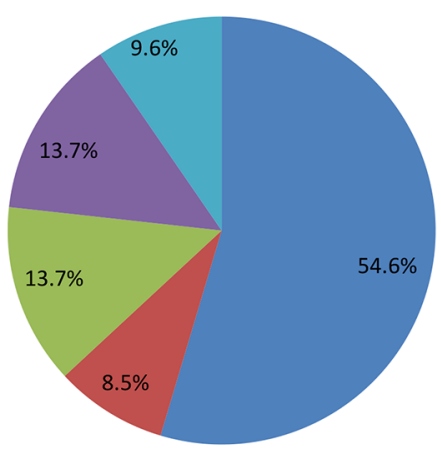

- Cytoplasm

Extracellular Space

nucleus

- Plasma Membrane

Other

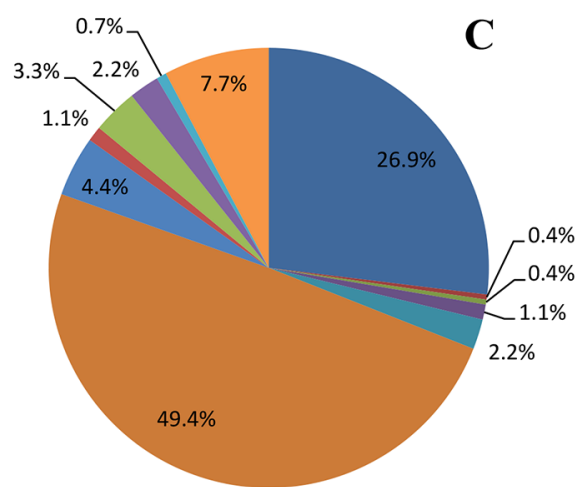

Figure 2: Proteomics analysis using Progenesis QI and IPA. A. Principal component analysis (PCA) of global protein profiles in PC-3 and PC-3RR xenograft tumors. Principal component 1 (PC1) and principal component 2 (PC2) were plotted. The blue data points (Left) represent the samples from PC-3RR xenograft tumors, and the pink data points (Right) represent the samples from PC-3 xenograft tumors. The blue and red clusters were well separated. B. Ontology analysis of the significantly altered proteins between PC-3 and PC-3RR xenografts. Cellular compartments of the differentially expressed proteins in PC-3RR compared to PC-3 control xenografts. C. Ontology analysis of the significantly altered proteins between PC-3 and PC-3RR xenografts. Functions of the differentially expressed proteins in PC-3RR compared to PC-3 control xenografts. 
regulation of the LDHA protein in PC-3RR tumors by re-examining the protein levels of LDHA from LC-MS/ MS results using Progenesis QI software, (Figure 4C). Furthermore, increased expression of LDHA mRNA was also confirmed in PC-3RR xenograft tumors compared with PC-3 tumors using qRT-PCR (Figure 4D). All these results indicate LDHA could be a potential therapeutic target for CaP RT.

\section{Radiosensitisation effect after knock down (KD) or inhibition of LDHA in PC-3RR cells}

To investigate the role of LDHA in CaP RT, LDHA was knocked down in PC-3RR cells using siRNA (LDHAsiRNA). The level of LDHA expression after KD was examined by Western blot. It was found that after 4 days of siRNA transfection, the cells became irregular and tended to detach from the bottom of the flask (data not shown) and that the maximum level of KD for LDHA was obtained at day 7 (D7) post siRNA transfection (Figure 5A). Although the maximum KD effect was achieved at day 7, all experiments were performed at day 4 post siRNA transfection to retain the viability of cells. In addition to the LDHA-siRNA, the LDHA specific inhibitor FX-11 was also used to inhibit LDHA activity in vitro. The dose response of PC-3RR cells to FX-11 treatment was determined using an MTT assay (Figure 5B). $\mathrm{IC}_{20}$ $(0.1 \mathrm{mM})$ for FX-11 from MTT assay was used for all following experiments.

To study the radiosensitization effect of $\mathrm{KD}$ or inhibition of LDHA using siRNA or FX-11 treatment, single RT or the combination of LDHA-siRNA (inhibitor FX-11) and RT treatments were performed for clonogenic ability (Figure 5C). It was found that the survival fractions at 4, 6, 8 Gy were significantly different between combinations of LDHA-siRNA/FX-11 inhibitor with RT and single RT controls (scr-siRNA or treatment with the equal volume of DMSO) in PC-3RR cells, respectively

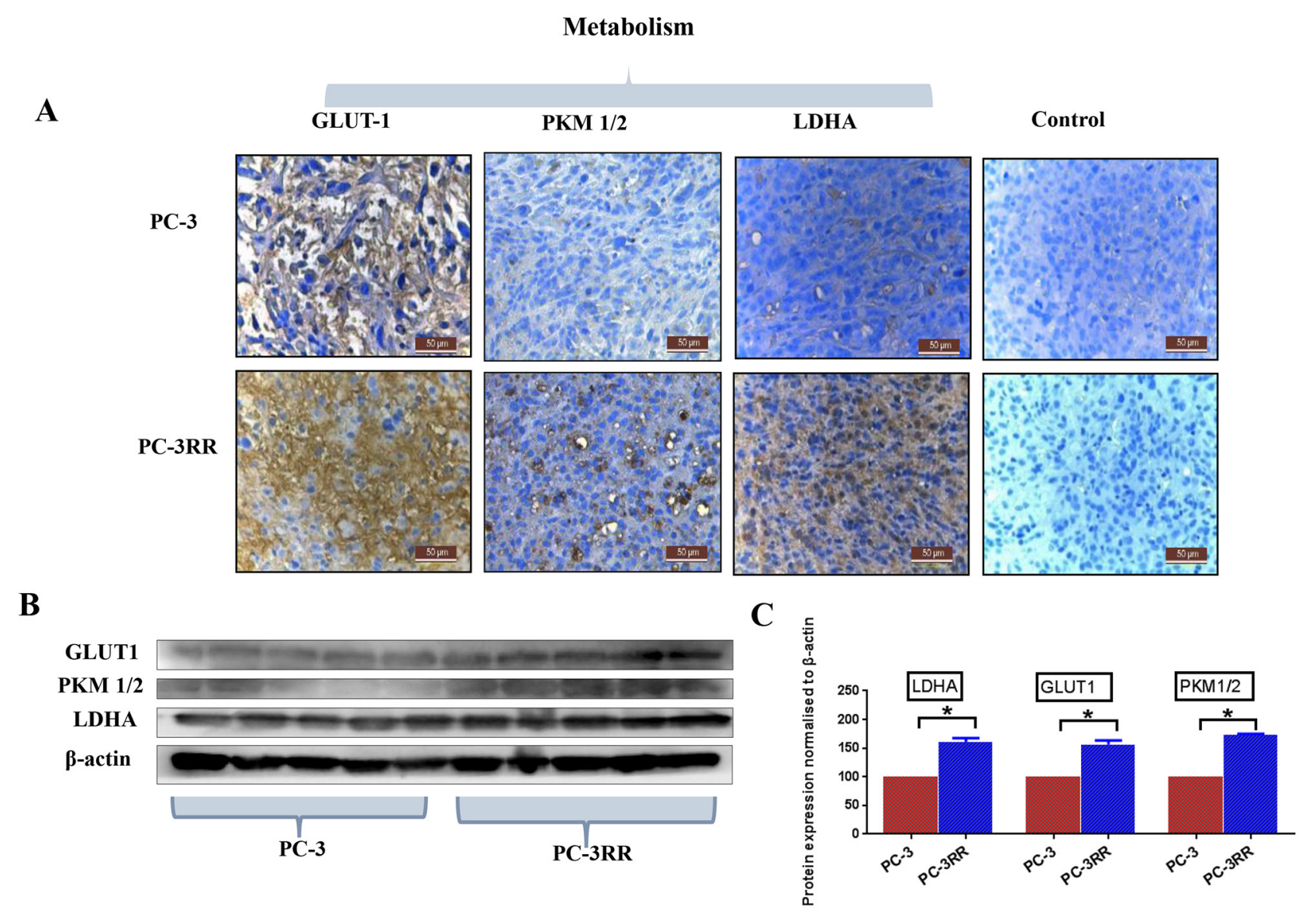

Figure 3: Validation of glycolysis proteins in PC-3 and PC-3RR xenografts. A. Validation of glycolysis proteins using IHC. The glycolysis pathway proteins GLUT-1, PKM1/2 and LDHA, were upregulated in PC-3RR xenografts compared to PC-3 xenografts. Brown indicates positive staining while blue indicates nuclei. Magnification x 400 in all images. B. Validation of glycolysis protein using Western blot. The upregulation of glycolysis pathway proteins GLUT-1, PKM1/2 and LDHA in PC-3RR xenografts were confirmed by Western blot. $\beta$-actin was used as a loading control. C. Quantification of Western blot results from PC-3 and PC-3RR xenografts. The results were normalized by the level of $\beta$-actin. Results are expressed as mean $\pm \operatorname{SD}(n=3)$. “*” indicates: $p<0.05$. Scale bar $=50 \mu \mathrm{m}$. 
$(p<0.05)(n=3)$, suggesting that KD or inhibition of LDHA led to markedly reduced clonogenic ability and sensitized PC-3RR cells to radiation.

\section{Effects of LDHA KD or inhibition on reactive oxygen species (ROS)}

As ROS plays an important role in radiationinduced cellular damage and cancer radioresistance [9], we investigated whether ROS is involved in the LDHAsiRNA and FX-11 mediated radiosensitization effects. Our results indicated that LDHA-siRNA or FX-11 treatment, combined with 6 Gy radiation, caused a significant increase of median fluorescence intensity (Figure 5D) and ROS levels (Figure 5E), compared to control groups in PC-3RR cells, respectively $(p<0.05)$.

\section{Effects of LDHA KD or LDHA inhibition on EMT, hypoxia, DSB, DNA repair pathway, apoptosis and autophagy proteins}

To further investigate mechanisms of combination of LDHA-siRNA or FX-11 and $\mathrm{RT}$ on $\mathrm{CaP}$ radiosensitization, the representative markers associated with EMT, hypoxia, DSB (DNA double-strand breaks), NHEJ (non-homologous end-joining inhibitor), apoptosis and autophagy were assessed in PC-3RR cells with different treatments and control treatments including: scr-siRNA control, scr-siRNA+6 Gy RT, LDHA-siRNA, LDHAsiRNA+6 Gy RT, vehicle control, vehicle control+6Gy RT, FX-11 and FX-11+6 Gy RT using Western blot.

Our results demonstrated that reduced N-Cadherin expression (EMT marker) was found in PC-3RR cells treated with LDHA-siRNA+RT and FX11+RT compared to the scr-siRNA and vehicle controls (Figure 6) while the suppression of LDHA with single LDHA-siRNA or FX-11 treatments also reduced N-Cadherin expression in PC-3RR cells compared to controls (Figure 6), indicating EMT may be involved in radiosensitization caused by LDHA-siRNA or FX11 inhibition.

To assess the level of hypoxia in LDHA-siRNA or FX11 inhibitor treated cells, the HIF-1 $\alpha$ was used as an indicator of hypoxia. We found that HIF-1 $\alpha$ was significantly reduced in combination of LDHA-siRNA or FX-11 and RT compared to scr-siRNA+RT or vehicle+RT treated cells (Figure 6), indicating that hypoxia is associated with combination treatment with LDHA-siRNA or FX-11and RT.

Our results also showed that the levels of DNA DSBs marker- $\gamma \mathrm{H} 2 \mathrm{AX}$ were significantly increased in
A
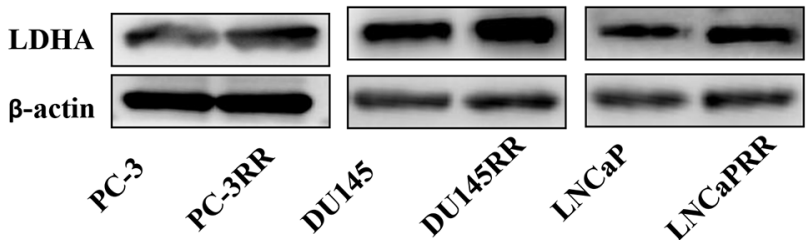

C

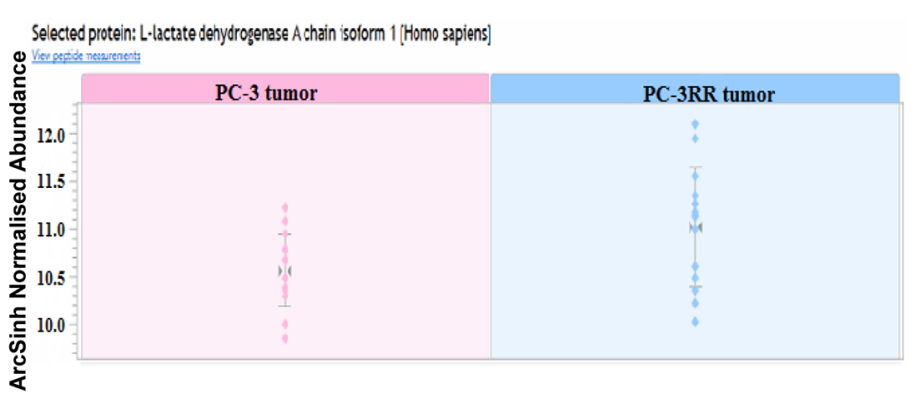

B

D

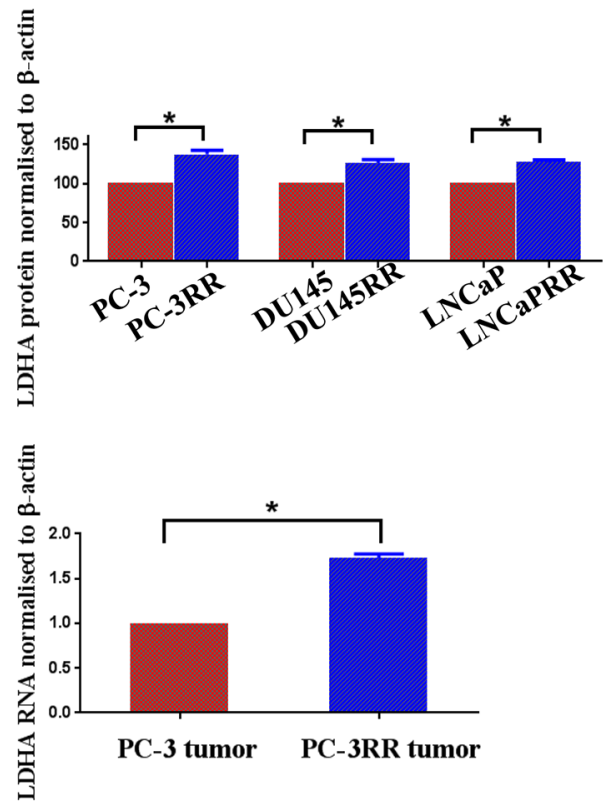

Figure 4: Expression of LDHA in CaP-RR cell lines and PC-3RR xenograft model. A. LDHA protein expression in CaP-RR cell lines. Higher levels of LDHA expression were seen in CaP-RR cell lines (PC-3RR, DU145-RR and LNCaP-RR) compared to their matching control cells. $\beta$-actin was used as a loading control. B. Quantification of Western blot results from CaP and CaP-RR cell lines. The results were normalized by the level of $\beta$-actin. Results are expressed as mean $\pm \mathrm{SD}(n=3)(p<0.05)$. C. Abundance of LDHA was shown using Progenesis IQ software. D. Validation of LDHA mRNA in PC-3 and PC-3RR xenografts. LDHA mRNA levels were detected using qRT-PCR and was normalized to $\beta$-actin level. Significantly increased LDHA mRNA was associated with PC-3RR xenografts $(p<0.05)$. “*” indicates: $p<0.05$. 
LDHA-siRNA, LDHA-siRNA+RT, FX-11, FX-11+RT, treated PC-3RR cells compared to scr-siRNA and scrsiRNA+RT or vehicle controls and vehicle+RT treated PC-3RR cells (Figure 6). Particularly, combination of LDHA-siRNA and RT significantly increased $\gamma \mathrm{H} 2 \mathrm{AX}$ level compared to vehicle+RT treatment and no obvious change was found between scr-siRNA or vehicle controls and scr-siRNA+RT or vehicle+RT treated cells (Figure 6), suggesting that there is a synergic effect by combination of LDHA-siRNA and RT in introducing DSBs in PC-3RR cells and improving radiosensitivity.

To evaluate the cellular response to DNA damage after RT, we examined the NHEJ DNA repair pathway protein $\mathrm{Ku} 70$ and found the level of $\mathrm{Ku} 70$ expression was significantly reduced in combination of LDHA-siRNA or FX-11 and RT compared to scr-siRNA+RT or vehicle+RT treatment (Figure 6), which is consistent with the DSB results and indicates the NHEJ DNA repair pathway plays an important role in combination of LDHA modulation or FX-11 inhibition and RT.

In addition, our results also indicated that single LDHA-siRNA or FX-11 treatment induced more apoptosis (increased Caspase-3-active) in PC-3RR cells compared to scr-siRNA or vehicle control and the combination of LDHA-siRNA/FX-11 and RT enhanced apoptosis to a higher extent (Figure 6). The findings of apoptosis by Western blot were confirmed by immunofluorescence staining (Supplementary Figure S1). Single LDHAsiRNA KD or FX-11 treatment slightly suppressed autophagy (decreased Beclin-1 level) in PC-3RR cells compared to scr-siRNA or vehicle control, and the combination of LDHA-siRNA/FX-11 and RT reduced Beclin-1 to a lower extent compared with LDHA-siRNA or FX-11 treatment alone (Figure 6). These results suggest

A

B
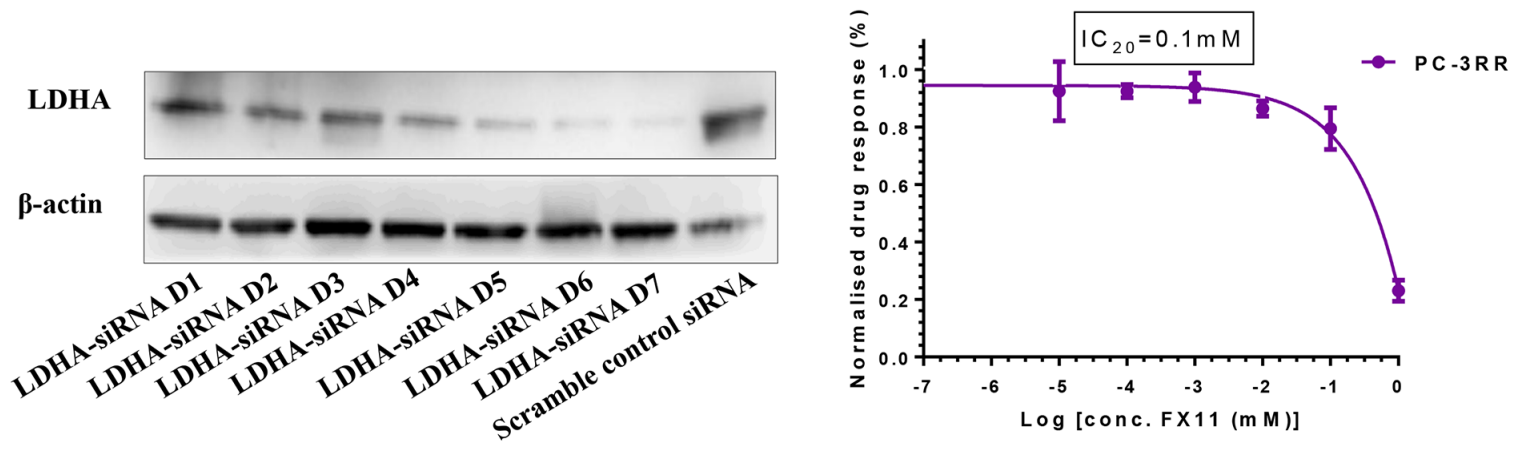

C

D

$\mathbf{E}$
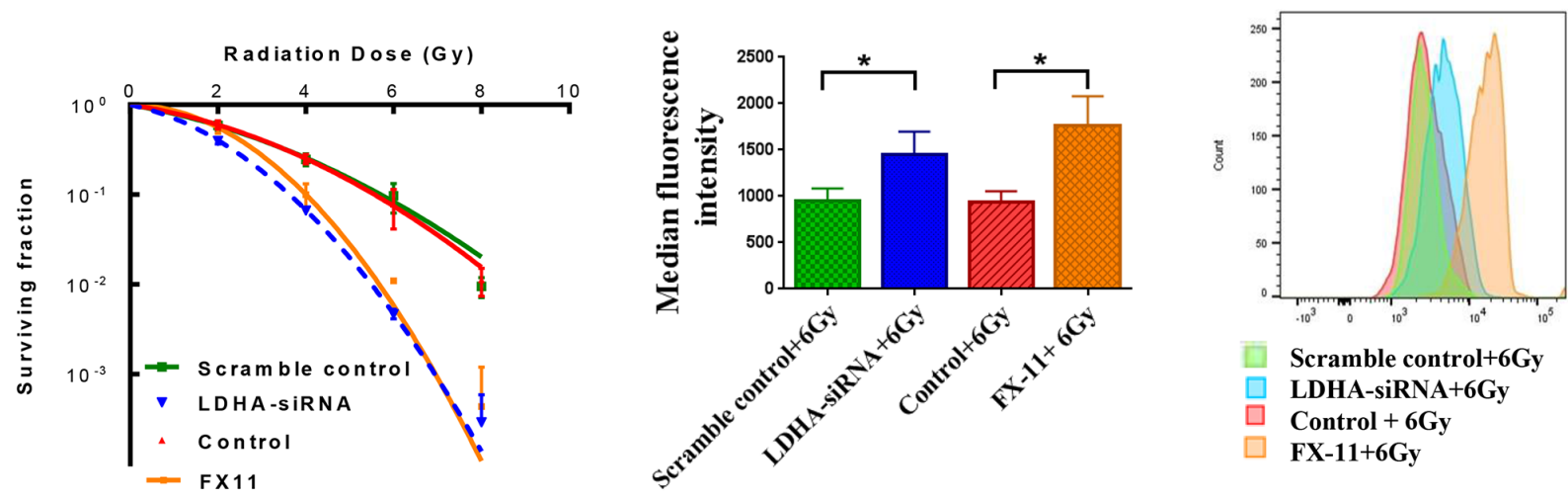

Figure 5: siRNA knocking down LDHA, MTT assay for FX-11 inhibitor, colony formation assay and ROS assay for single RT and combination treatments. A. siRNA knocking down LDHA. LDHA protein expression was observed at 1-7 days post LDHA-siRNA and scr-siRNA transfection. B. MTT assay for FX-11 inhibitor. PC-3RR cells were treated with FX-11 in final concentrations of $0-1 \mathrm{mM}$. The $\mathrm{IC}_{20}$ value was calculated to be $0.1 \mathrm{mM}$. C. Colony formation assay. PC-3RR cells were treated with combination of LDHA-siRNA (scr-siRNA) or FX-11 (vehicle) with RT (2, 4, 6, and 8 Gy) for analysis of colony-forming efficiency. Survival fractions were significantly reduced in PC-3RR cells after LDHA-siRNA+RT or FX-11+RT treatments compared to control combination treatments $(p<0.05$ at 4, 6, 8 Gy). D. ROS analysis by flow cytometry. After specific combination treatments or control combination treatments, intracellular ROS production was measured by flow cytometry. As shown by the median fluorescent intensity, significantly higher levels of ROS were detected in combination of LDHA-siRNA and RT or FX-11 and RT in PC-3RR cells compared with scr-siRNA+RT or vehicle+RT $(p<0.05)$. E. The representative image of histograms of ROS after single RT or combination treatments. All results were from three independent experiments $(\mathrm{n}=3)$. “*” indicates: $p<0.05$ 
apoptosis and autophagy mechanisms are associated with LDHA downregulation or FX-11 inhibition mediated CaP radiosensitization. The changes of EMT, hypoxia, DSB, NHEJ, apoptosis, and autophagy pathway markers in PC3RR cells with different treatments are summarized in Table 1.

\section{DISCUSSION}

In the current study, we firstly developed PC-3RR s.c xenograft tumor model for proteomic biomarker discovery of interesting therapeutic targets. While there was no obvious difference in growth rates between PC-

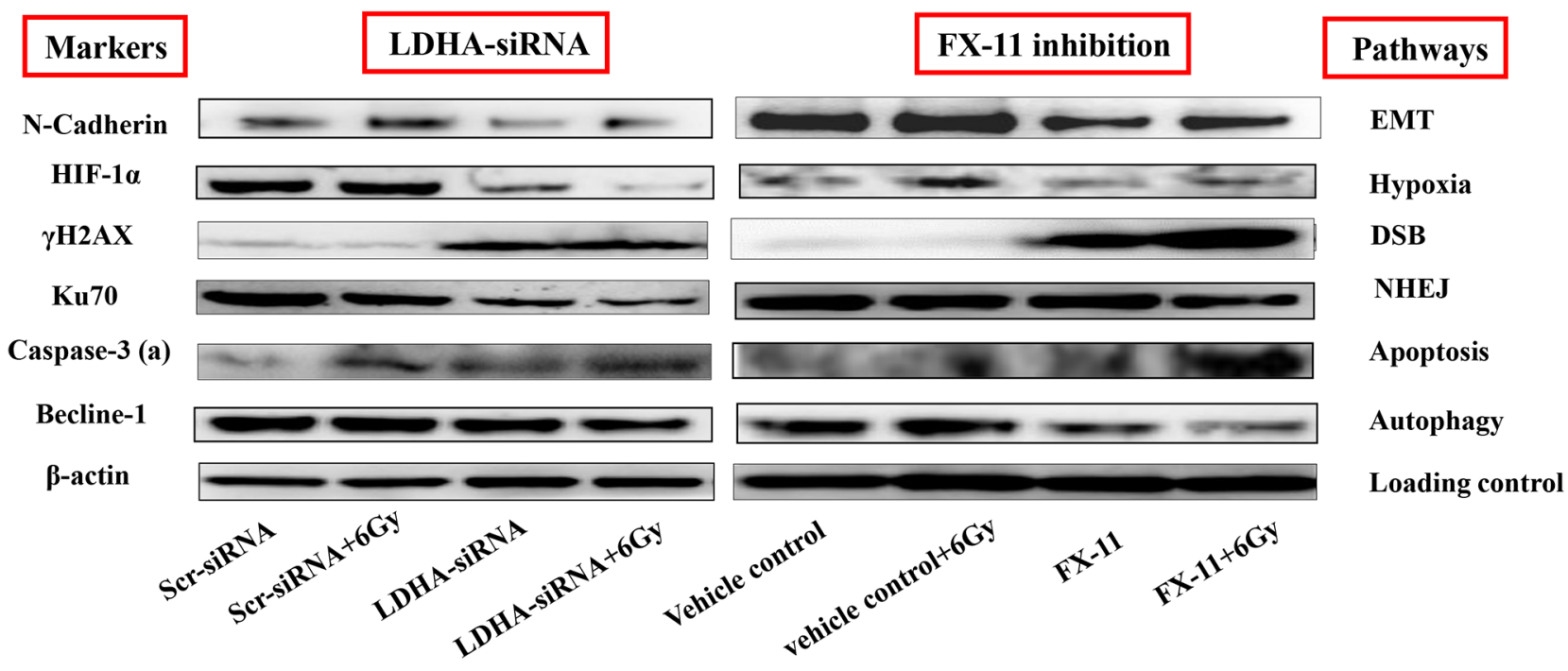

Figure 6: The putative mechanisms of radiosensitisation caused by LDHA-siRNA downregulation or FX-11 inhibition in PC-3RR cells. Expression of N-Cadherin (EMT), HIF-1 $\alpha$ (hypoxia), $\gamma \mathrm{H} 2 \mathrm{AX}$ (DNA DSB), Ku70 (DNA repair), Caspase-3 (active) (apoptosis) and Becline-1 (autophagy) was studied by Western blot after different treatments. The expressions of N-Cadherin and Becline-1 were decreased in either LDHA-siRNA+RT or FX-11+RT treatment compared to scr-siRNA+RT or vehicle+RT, while the levels of $\gamma H 2 \mathrm{AX}$ and caspase-3 (active) were increased in either LDHA-siRNA+RT or FX-11+RT treatment compared to scr-siRNA+RT or vehicle+RT. The levels of HIF-1 $\alpha$ and Ku70 were significantly reduced after combination of LDHA-siRNA or FX-11 and RT treatment compared to RT plus vehicle treatment. $\beta$-actin was used as a loading control. Note: "caspase-3 (a)" indicates caspase-3 (active)"

Table 1: The changes of EMT, hypoxia, DSB, NHEJ, apoptosis, and autophagy pathway markers in PC-3RR cells with different treatments

\begin{tabular}{|c|c|c|c|c|c|c|}
\hline $\begin{array}{l}\text { Pathway/ } \\
\text { function }\end{array}$ & $\begin{array}{c}\text { LDHA-siRNA } \\
\text { vs scr-siRNA }\end{array}$ & $\begin{array}{c}\text { LDHA- } \\
\text { siRNA+RT vs } \\
\text { LDHA-siRNA }\end{array}$ & $\begin{array}{c}\text { LDHA- } \\
\text { siRNA+RT vs } \\
\text { scr-siRNA+RT }\end{array}$ & $\begin{array}{l}\text { FX-11 vs } \\
\text { vehicle control }\end{array}$ & $\begin{array}{c}\text { FX-11+RT } \\
\text { vs FX-11 }\end{array}$ & $\begin{array}{c}\text { FX-11+RT } \\
\text { vs vehicle } \\
\text { control+RT }\end{array}$ \\
\hline $\begin{array}{l}\text { EMT } \\
\text { (N-Cadherin) }\end{array}$ & - & + & - & - & + & - \\
\hline Hypoxia (HIF- $\alpha$ ) & - & - & - & $=$ & + & - \\
\hline $\mathrm{DSB}(\gamma \mathrm{H} 2 \mathrm{AX})$ & + & $=$ & + & + & + & + \\
\hline NHEJ (Ku70) & - & - & - & $=$ & - & - \\
\hline $\begin{array}{l}\text { Apoptosis } \\
\text { (Caspase-3- } \\
\text { active) }\end{array}$ & + & + & + & + & + & + \\
\hline $\begin{array}{l}\text { Autophagy } \\
\text { (Becline-1) }\end{array}$ & - & - & - & - & - & - \\
\hline
\end{tabular}

Notes: "+" pathway is enhanced; "-" pathways is suppressed; "=" no significant change. The results are from three independent experiments. 
3RR tumors and PC-3 control tumors, the PC-3RR tumors were less responsive to radiation treatment compared to PC-3 control tumors (unpublished observation), suggesting that the RR characteristics were retained in the PC-3RR xenografts in vivo. It is well known that angiogenesis, hypoxia, EMT and CSC play very important roles in cancer radioresistance [10]. In PC3RR tumors, we demonstrated increased angiogenesis (CD31 and VEGFR2) and hypoxia (HIF-1 $\alpha$ ) as well as enhanced EMT (increased N-Cadherin and reduced E-Cadherin) and elevated CSC markers' expression (CD44 and Oct-4), which is consistent with our previous in vitro study in CaP-RR cells [8], further confirming that angiogenesis, hypoxia, EMT and CSC are involved in $\mathrm{CaP}$ radioresistance and this model is very suitable for studying $\mathrm{CaP}$ radioresistance.

With LC-MS/MS analysis, 378 DEPs were identified between PC-3 and PC-3RR tumor xenografts. PCA data indicated a satisfactory separation of two groups of samples from PC-3 and PC-3RR xenograft tumors. Pathway enrichment analysis could demonstrate 51 pathways to be deregulated in PC-3RR tumors. Among them, 37 pathways are reported to be associated with $\mathrm{CaP}$ using Pubmed (http://www.ncbi.nlm.nih.gov/pubmed) database search. Our results indicate that top five pathways associated with $\mathrm{CaP}$ radioresistance (ordered according to the number of $\mathrm{CaP}$ related publications from Pubmed database) are: VEGF signaling, Integrin signaling, IGF1 signaling, Glycolysis I and Protein Kinase A signaling. These findings suggest that $\mathrm{CaP}$ radioresistance is regulated by a multiple protein network and various important signaling pathways, and that management of these proteins or signaling pathways is promising to develop novel therapies to improve CaP RT.

A number of studies have demonstrated that increased aerobic tumor metabolism (glycolysis) is highly associated with the development of radioresistance by providing a chemically reduced milieu in the tumor microenvironment [11] and inhibition of glycolysis resulted in increased radiosensitivity [12]. The roles of glycolysis in $\mathrm{CaP}$ radioresistance are still unclear. Due to the importance of glycolysis in cancer radioresistance and its close link with angiogenesis, hypoxia, EMT and CSC [1317], this pathway was chosen for further validation. It was found that the key glycolysis pathway proteinsGLUT-1, PKM1/2 and LDHA were increased in PC3RR xenograft tumors compared to PC-3 tumors, further confirming the activation of glycolysis pathway in $\mathrm{CaP}$ radioresistance.

LDHA is a main metabolic enzyme for lactate production which is a terminal product from glycolysis. It is one of the important glycolysis pathway proteins which catalyzes the inter-conversion of pyruvate and lactate. Several lines of evidence indicate that elevated levels of LDHA correlate with a higher grade of aerobic glycolysis and with poor prognosis in cancers [18-21]. It was reported that the high levels of lactate and LDHA are associated with poor response to radiation treatments in head and neck squamous cell carcinoma (HNSCC) [22, 23]. Yamada et al. found that high level of serum LDHA is indicative of poor prognosis in $\mathrm{CaP}$ [24]. Koukourakis et al. conducted a study on 83 human CaP biopsies and found that LDH5, an isoform encoded by LDHA gene, is significantly associated with biomedical failure after RT [25], indicating that LDH family is associated with $\mathrm{CaP}$ radioresistance. The current study demonstrated that higher levels of LDHA expression were found in CaP-RR cells and PC-3RR xenograft tumors, suggesting that LDHA could be a hallmark in $\mathrm{CaP}$ radioresistance, and LDHA down-regulation and inhibition both lead to radiosensitization of CaP-RR cells, which is consistent with the result of LDH5 by Koukourakis et al [25]. The role of LDHA in $\mathrm{CaP}$ radioresistance is still unclear. Therefore, a series of functional studies were performed to investigate the mechanisms and pathways that are involved in the LDHA reduction mediated $\mathrm{CaP}$ radiosensitization.

ROS has an important implication in cancer radioresistance [9]. As a key event in RT-induced biological processes, it is widely involved in DNA damage, cell cycle arrest and apoptosis [26]. In this study, we found knocking down LDHA using siRNA or treatment with a specific LDHA inhibitor FX-11 combined with RT could increase radiosensitivity in PC3RR cells accompanied with increased ROS, which is in line with the findings in CaP cell lines treated with LDHA siRNA or LDHA inhibitor by Koukourakis et al [25]. A previous report demonstrated that driving glycolysis and degradation of glucose to lactate supports diminishing of oxidative stress [27]. KD of LDHA was reported to contribute to the increase of mitochondrial ROS, because of the redirection of metabolism away from lactate as the end product, favouring rather the conversion of pyruvate to acetyl-coA and entering the TCA cycle in mitochondria for breast cancer [28]. It was shown that FX-11 treatment induces oxidative stress and cell death in the P493 human lymphoma B cells in vitro and inhibited human lymphoma progression [29]. These results suggest that LDHA modulation-induced radiosensitization might partly result from ROS. Therefore, reduction of LDHA-mediated glycolysis in this study could be regarded as a driver of oxygen consumption, which resulted in high level of ROS, and increased ROS in combination treatment can lead to cell death [29].

Our recent study demonstrated that EMT could be a factor leading to the acquisition of $\mathrm{CaP}$ radioresistance [8]. Shintani et al. also found that increased EMT is associated with resistance of non-small cell lung cancer (NSCLC) to RT or chemotherapy [30]. Kim et al. reported that microRNA (miR)-34a mediated targeting of EMT increased in vivo radiosensitivity in a NSCLC xenograft mouse model [31]. In the current study, we showed that 
single LDHA-siRNA or FX-11 inhibition resulted in reduction of EMT, and combination treatments reduced EMT compared to single RT, suggesting that reversal of EMT by LDHA modulation could be another possible mechanism for radiosensitizaion in CaP-RR cells.

HIF- $1 \alpha$ is stabilized and accumulated under hypoxia. Ample evidence showed that it up-regulates glycolysis genes [32] including LDHA in CaP [33]. An earlier study proved a hypoxia response element was present in the promoter region of the LDHA gene [34]. KD of LDHA and HIF- $1 \alpha$ was reported to restore sensitivity to a chemodrug on multiple myeloma cell lines [35]. Hypoxic cells are believed to be more resistant to radiation treatment compared to non-hypoxic cells [36]. When normoxia is dominant rather than hypoxia, activation of various tumor survival and angiogenesis genes is inhibited [29]. Reoxygenation after RT is regarded to improve the outcome of RT [37]. Inhibition of LDHA in human P493 B-lymphoid cells resulted in inhibition of hypoxia [29], indicating LDHA and hypoxia are correlated. In this study, we showed that the HIF-1 $\alpha$ was downregulated by LDHAsiRNA combined with RT, suggesting hypoxia could be suppressed by reduced LDHA, thus leading to inhibition of tumor survival genes and promoting radiosensitization.

A critical marker of RT-induced DNA DSBs is the phosphorylation of histone $\gamma \mathrm{H} 2 \mathrm{AX}$ [38], which is an indicator of the DSB repair ability after RT [39]. Escalated DSB was observed in PC-3RR cells at both LDHA KD and inhibition of LDHA alone. Combination of LDHA KD or inhibition with RT, further increased DSB in PC-3RR cells compared to RT treatment alone. Furthermore, the DNA DSB repair via NHEJ pathway, as indicated by Ku70 level, was significantly abrogated in LDHA KD, or even depleted in the LDHA KD plus RT treated cells. However, the impaired NHEJ DNA repair mechanism was not obvious in FX-11 treatments as in LDHA KD, suggesting LDHA inhibition by FX-11 does not completely confer DNA repair ability through NHEJ pathway, and the FX11 treated cells still retain DNA repair ability via other pathways.

Apoptosis has a crucial role in cell death after RT, and autophagy is called as 'the second apoptosis'. In cancer therapy, the role of autophagy is paradoxical, in which this cellular process may serve as a pro-survival or pro-death mechanism to counteract or mediate the cytotoxic effect of anticancer agents [40]. Le et al. found that silencing or inhibition of LDHA increased apoptosis possibly via induced oxidative stress [29]. As previous described, targeting autophagy was considered as an effective way of overcoming radioresistance [41]. Meng et al. demonstrated that silencing PKM2 in the glycolysis pathway was shown to sensitize RT in NSCLC via inhibiting autophagy [12]. It was also reported that inhibition of autophagy by rapamycin and apoptosis inducer could effectively sensitize a lung cancer cell line to radiation [42]. In this study, we found that combination of LDHA-siRNA or FX-11 inhibitor with RT both markedly increased apoptosis and reduced autophagy level, suggesting that both apoptosis and autophagy are involved in $\mathrm{CaP}$ radiosensitization effect.

The functional studies have proved that LDHA $\mathrm{KD}$ or inhibition can lead to the changes of ROS, EMT, hypoxia, DSB, apoptosis and autophagy, thus resulting in the sensitization of CaP RR cells. Because of its tight linkage to different pathways, LDHA is revealed to be not only a hallmark of $\mathrm{CaP}$ radioresistance but also a favorable target for radiosensitization treatment of the CaP-RR patients.

In summary, in this study, we have identified a list of potential RR markers and important signaling pathways from PC-3RR xenograft mouse model, and found that LDHA is a potential therapeutic target associated with $\mathrm{CaP}$ radioresistance. In addition, we demonstrate that the radiosensitization effect of combination of interfering LDHA with RT is associated with enhanced ROS, apoptosis and DSBs as well as reduced EMT and autophagy. Our findings suggest that LDHA is an ideal therapeutic target to develop combination therapy to overcome $\mathrm{CaP}$ radioresistance.

\section{MATERIALS AND METHODS}

\section{Cell lines and cell culture}

PC-3, DU145, LNCaP cell lines were obtained from American Type Culture Collection (ATCC) (Rockville, MD, USA). PC-3RR, DU145RR, and LNCaPRR cell lines were developed and the confirmed in our previous study [8]. All cell lines used were cultured in RPMI-1640 medium supplemented with $10 \%$ heated-inactivated fetal bovine serum (FBS), $50 \mathrm{U} / \mathrm{mL}$ of penicillin and $50 \mu \mathrm{g} /$ $\mathrm{mL}$ of streptomycin. All cell lines were maintained in a humidified incubator at $37^{\circ} \mathrm{C}$ and $5 \% \mathrm{CO}_{2}$. The identities of all cell lines were confirmed by short tandem repeat profiling. All cell lines were regularly tested to confirm the absence of mycoplasma contamination using the LookOut ${ }^{\circledR}$ mycoplasma PCR detection kit (Sigma-Aldrich Pty Ltd, NSW, Australia).

\section{Antibodies}

Antibodies were obtained from different sources. The detailed information and conditions for all antibodies are listed in Table 2.

\section{Establishment of PC-3 and PC-3RR animal xenograft models in vivo}

Seven weeks male NOD/SCID mice (Animal Resources Centre, Western Australia) were housed under specific pathogen-free conditions in facilities approved by the University of New South Wales (UNSW) Animal 
Table 2: Antibodies used for western blot (WB), immunofluorescence (IF) and immunohistochemistry (IHC) staining

\begin{tabular}{|c|c|c|c|c|c|c|}
\hline Antibody & Source & Type & Dilution & $\begin{array}{c}\text { Incubation } \\
\text { time }\end{array}$ & Temperature & Application \\
\hline Rabbit anti-E-Cadherin antibody & Abcam & $\mathrm{PAb}$ & $1: 100$ & $\mathrm{O} / \mathrm{N}$ & $4^{\circ} \mathrm{C}$ & $\mathrm{IHC}$ \\
\hline $\begin{array}{l}\text { Rabbit anti-human N-Cadherin } \\
\text { antibody }\end{array}$ & Abcam & $\mathrm{PAb}$ & $1: 500$ & $\mathrm{O} / \mathrm{N}$ & $4^{\circ} \mathrm{C}$ & IHC,WB \\
\hline $\begin{array}{l}\text { Rabbit anti-human Ku70 } \\
\text { antibody }\end{array}$ & Abcam & $\mathrm{PAb}$ & $1: 1000$ & $\mathrm{O} / \mathrm{N}$ & $4^{\circ} \mathrm{C}$ & WB \\
\hline $\begin{array}{l}\text { Rabbit anti-human } \gamma \mathrm{H} 2 \mathrm{AX} \\
\text { antibody }\end{array}$ & Abcam & $\mathrm{PAb}$ & $1: 1000$ & $\mathrm{O} / \mathrm{N}$ & $4 \mathrm{oC}$ & WB \\
\hline $\begin{array}{l}\text { Rabbit anti-human active } \\
\text { Caspase- } 3 \text { antibody }\end{array}$ & Abcam & $\mathrm{PAb}$ & $1: 500$ & $\mathrm{O} / \mathrm{N}$ & $4^{\circ} \mathrm{C}$ & WB \\
\hline Rabbit anti-Becline- 1 antibody & $\begin{array}{l}\text { Cell signalling } \\
\text { Technology }\end{array}$ & PAb & 1:1000 (WB) & $\mathrm{O} / \mathrm{N}$ & $4^{\circ} \mathrm{C}$ & WB \\
\hline $\begin{array}{l}\text { Rabbit anti-human Becline-1 } \\
\text { antibody }\end{array}$ & $\begin{array}{l}\text { Cell signalling } \\
\text { Technology }\end{array}$ & $\mathrm{PAb}$ & $1: 1000$ & $\mathrm{O} / \mathrm{N}$ & $4^{\circ} \mathrm{C}$ & WB \\
\hline $\begin{array}{l}\text { Mouse anti-human Beta-actin } \\
\text { antibody }\end{array}$ & Sigma Altrich & MAb & $1: 5000$ & $\mathrm{O} / \mathrm{N}$ & $4^{\circ} \mathrm{C}$ & WB \\
\hline Rat anti-mouse CD31 antibody & $\mathrm{BD}$ pharmingen & MAb & $1: 100$ & $\mathrm{O} / \mathrm{N}$ & $4^{\circ} \mathrm{C}$ & $\mathrm{IHC}$ \\
\hline Rabbit anti-VEGFR2 antibody & Abcam & PAb & $1: 100$ & $\mathrm{O} / \mathrm{N}$ & $4^{\circ} \mathrm{C}$ & $\mathrm{IHC}$ \\
\hline Mouse anti-CD44 antibody & $\begin{array}{c}\text { Santa Cruz } \\
\text { Biotechnology }\end{array}$ & MAb & $1: 200$ & $\mathrm{O} / \mathrm{N}$ & $4^{\circ} \mathrm{C}$ & $\mathrm{IHC}$ \\
\hline Rabbit anti-Oct4 antibody & Abcam & $\mathrm{PAb}$ & $1: 500$ & $\mathrm{O} / \mathrm{N}$ & $4^{\circ} \mathrm{C}$ & $\mathrm{IHC}$ \\
\hline $\begin{array}{l}\text { Mouse anti-human HIF-1 } \alpha \\
\text { antibody }\end{array}$ & Abcam & MAb & $\begin{array}{l}1: 500(\mathrm{WB}) \\
1: 100(\mathrm{IHC})\end{array}$ & $\mathrm{O} / \mathrm{N}$ & $4^{\circ} \mathrm{C}$ & IHC, WB \\
\hline $\begin{array}{l}\text { Rabbit anti-human PKM1/2 } \\
\text { antibody }\end{array}$ & Cell signalling & PAb & $\begin{array}{l}1: 1000(\mathrm{WB}) \\
1: 100(\mathrm{IHC})\end{array}$ & $\mathrm{O} / \mathrm{N}$ & $4^{\circ} \mathrm{C}$ & IHC, WB \\
\hline $\begin{array}{l}\text { Rabbit anti-human GLUT-1 } \\
\text { antibody }\end{array}$ & Abcam & PAb & $\begin{array}{l}1: 1000(\mathrm{WB}) \\
1: 100(\mathrm{IHC})\end{array}$ & $\mathrm{O} / \mathrm{N}$ & $4^{\circ} \mathrm{C}$ & IHC, WB \\
\hline $\begin{array}{l}\text { Rabbit anti-human LDHA } \\
\text { antibody }\end{array}$ & Abcam & PAb & $\begin{array}{l}1: 2000(\mathrm{WB}) \\
1: 400(\mathrm{IHC})\end{array}$ & $\mathrm{O} / \mathrm{N}$ & $4^{\circ} \mathrm{C}$ & IHC, WB \\
\hline $\begin{array}{l}\text { Goat anti-rabbit Alexa Fluor }{ }^{\circledR} \\
488 \text { Dye Conjugate }\end{array}$ & Invitrogen & $\operatorname{IgG}$ & $1: 1000$ (IF) & 60 mins & $\mathrm{rt}$ & IF \\
\hline Goat anti-rabbit IgG-HRP & $\begin{array}{c}\text { Santa Cruz } \\
\text { Biotechnology }\end{array}$ & $\mathrm{PAb}$ & $1: 2000$ & 45 mins & $\mathrm{rt}$ & WB \\
\hline Goat anti-mouse IgG-HRP & $\begin{array}{c}\text { Santa Cruz } \\
\text { Biotechnology }\end{array}$ & $\mathrm{PAb}$ & $1: 2000$ & 45 mins & $\mathrm{rt}$ & WB \\
\hline $\begin{array}{l}\text { Rabbit anti-rat } \\
\text { immunoglobulins, biotinlyated }\end{array}$ & Dako Pty. Ltd. & PAb & $1: 100$ & 45 mins & $\mathrm{rt}$ & $\mathrm{IHC}$ \\
\hline Goat anti-rabbit IgG-HRP & Dako Pty. Ltd. & $\mathrm{PAb}$ & $1: 100$ & 45 mins & $\mathrm{rt}$ & $\mathrm{IHC}$ \\
\hline Rabbit anti-mouse IgG-HRP & Dako Pty. Ltd. & PAb & $1: 100$ & 45 mins & $\mathrm{rt}$ & $\begin{array}{l}\mathrm{IHC} \\
\text { (Continued) }\end{array}$ \\
\hline
\end{tabular}




\begin{tabular}{lcccccc}
\hline Antibody & Source & Type & Dilution & $\begin{array}{c}\text { Incubation } \\
\text { time }\end{array}$ & Temperature & Application \\
\hline $\begin{array}{l}\text { Mouse anti-human IgG1- } \\
\text { negative }\end{array}$ & Dako Pty. Ltd. & IgG & $1: 100$ & $\mathrm{O} / \mathrm{N}$ & $4^{\circ} \mathrm{C}$ & $\mathrm{IHC}$ \\
$\begin{array}{l}\text { Rabbit anti-human IgG1- } \\
\text { negative }\end{array}$ & Dako Pty. Ltd. & $\operatorname{IgG}$ & $1: 100$ & $\mathrm{O} / \mathrm{N}$ & $4^{\circ} \mathrm{C}$ & $\mathrm{IHC}$ \\
\hline
\end{tabular}

Notes: HRP: horseradish peroxide;IF: immunofluorescence;IHC: immunohistochemistry; MAb: monoclonal antibody; $\mathrm{O} / \mathrm{N}$ : overnight; PAb: polyclonal antibody; rt: room temperature; WB: Western Blot.

Care and Ethics Committee (ACEC) (ACEC 13/118B). Mice were kept at least 1 week before experimental manipulation. All mice remained healthy and active during the experiments. The $\mathrm{CaP}$ s.c model was established following our published method [43]. Briefly, cultured PC-3 and PC-3RR cells $\left(2 \times 10^{6}\right.$ /injection $)$ in $100 \mathrm{uL}$ Dulbecco's Phosphate-Buffered Saline (DPBS) were implanted subcutaneously in the right rear flank region of mice ( $\mathrm{n}=5$ mice/per group). Tumor progression was documented weekly by measuring tumor sizes using callipers. Tumor volumes were calculated as follows: length $\mathrm{x}$ width $\mathrm{x}$ height $\mathrm{x} 0.52$ (in millimetres) [44].

For growth rate study, the mice were euthanized 7 weeks post cell inoculation. For each tumor, half were snap-frozen using liquid nitrogen for proteomics study and the rest separated for paraffin embedding and frozen sectioning for histological examination and IHC.

\section{Preparation of protein samples for LC-MS/MS}

Frozen PC-3 or PC-3RR xenograft tissues were minced with stainless steel scalpels. The mince tissues were then ground in liquid nitrogen in a mortar using a pestle. The tissue powder was resuspended using lysis buffer $(50 \mathrm{mmol} / \mathrm{L}$ Tris- $\mathrm{HCl}(\mathrm{pH} 8.0), 150 \mathrm{mmol} / \mathrm{L}$ $\mathrm{NaCl}, 0.1 \%$ sodium dodecyl sulfate (SDS), $10 \mathrm{mmol} / \mathrm{L}$ $\mathrm{NaF}, 1 \mathrm{mmol} / \mathrm{L} \mathrm{Na} \mathrm{VO}_{4}, 0.5 \%$ sodium deoxycholate and $1 \%$ Triton $\mathrm{X}-100$ ) at a ratio of $1 \mathrm{mg}$ tissue: $5 \mathrm{~mL}$ buffer, followed by a bead beating method. Briefly, $0.13 \mathrm{~g}$ zirconium beads $(0.1 \mathrm{~mm}$ diameter $) / 100 \mu \mathrm{L}$ of lysis buffer were added into mixture, and bead beating was performed on the highest setting for 80 seconds and returned to ice for 5 mins. Bead beating was repeated 4 times. Solution was centrifuged at $30000 \mathrm{~g}$ for $40 \mathrm{~min}$ and the supernatant was collected. Protein concentration was determined by the BCA protein assay kit (Pierce, USA). Protein samples were digested according to a published method [45]. A total of $100 \mu \mathrm{g}$ of total cell lysate from each sample was precipitated in 100\% ice-cold acetone at 1:4 (v/v) protein solution:acetone dilution. Trypsin (in $50 \mathrm{mM}$ ammonium bicarbonate buffer, $\mathrm{pH} 8.5$ ) was added at an enzyme/substrate ratio of 1:100 (w/w) and the samples were incubated overnight $(\mathrm{o} / \mathrm{n})$ to allow for digestion. The lyophilized samples were eluted by using C18 stage tips and collected in mass spectrometry tubes.

\section{LC-MS/MS}

LC-MS/MS analysis was carried out for PC-3 and PC-3RR xenograft samples using an LTQ Orbitrap Velos ETD (Thermo Scientific, US) at Bioanalytical Mass Spectrometry Facility (BMSF), UNSW. Digested peptides were reconstituted in $10 \mu \mathrm{L} 0.1 \%$ formic acid and separated by nano-LC using an Ultimate 3000 HPLC and autosampler (Dionex, Amsterdam, Netherlands). The sample $(0.2 \mu \mathrm{L})$ was loaded onto a micro $\mathrm{C} 18$ pre-column $(300 \mu \mathrm{m} \times 5 \mathrm{~mm}$, Dionex, Scoresby, VIC, Australia) with Buffer A $\left(98 \% \mathrm{H}_{2} \mathrm{O}, 2 \% \mathrm{CH}_{3} \mathrm{CN}, 0.1 \% \mathrm{TFA}\right)$ at $10 \mu \mathrm{L} /$ min. After washing, the pre-column was switched (Valco 10 port valve, Dionex) into line with a fritless nano column $(75 \mu \mathrm{m}$ i.d $\times 15 \mathrm{~cm})$ containing reverse phase $\mathrm{C} 18$ media ( $3 \mu \mathrm{m}, 200 \AA$ Magic, Michrom Bioresoures). Peptides were eluted using a linear gradient of Buffer A to Buffer B ( $98 \% \mathrm{CH}_{3} \mathrm{CH}, 2 \% \mathrm{H}_{2} \mathrm{O}, 0.1 \%$ formic acid) at $0.25 \mu \mathrm{L} /$ min over $60 \mathrm{~min}$. High voltage $(2000 \mathrm{~V})$ was applied to low volume tee (Upchurch Scientific, Oak Harbor, WA, USA) and the column tip positioned $0.5 \mathrm{~cm}$ from the heated capillary $\left(T=280^{\circ} \mathrm{C}\right)$ of an Orbitrap Velos (Thermo Electron, Bremen, Germany) mass spectrometer. Positive ions were generated by electrospray and the Orbitrap was operated in a data-dependent acquisition (DDA) mode. A survey scan 350-1750 m/z was acquired in the Orbitrap (Resolution=30000 at $400 \mathrm{~m} / \mathrm{z}$, with an accumulation target value of 1000000 ions) with lockmass enabled. Up to the 10 most abundant ions (>5000 counts) with charge states +2 to +4 were sequentially isolated and fragmented within the linear ion trap using collisionally induced dissociation with an activation $q=0.25$ and activation time of $30 \mathrm{~ms}$ at a target value of 30000 ions. The $\mathrm{m} / \mathrm{z}$ ratios selected for MS/MS were dynamically excluded for 30 s [46].

\section{Progenesis QI analysis}

MS peak intensities were analyzed using Progenesis QI data analysis software v4 (Waters). Ion intensity maps from each run were aligned to a reference sample and ion feature matching was achieved by aligning consistent ion $\mathrm{m} / \mathrm{z}$ and retention times. The peptide intensities were normalized against total intensity (sample specific log-scale abundance ratio scaling factor) and compared 
between groups by one-way analysis of variance (ANOVA, $p \leq 0.05$ for statistical significance) and post hoc multiple comparison procedures. Type I errors were controlled by False Discovery Rate (FDR) with $q$ value significance set at 0.01 [47]. Results are reported as mean \pm SD (normalized ion intensity score).

\section{Protein dataset}

Peak lists of proteins were generated using Mascot Daemon/extract_msn (Matrix Science, Thermo, London, UK) using the default parameters, and submitted to Mascot 2.1 (Matrix Science). All MS/MS spectra of differentiating peptides were searched against human non-redundant NCBInr database using the Mascot search program (Matrix Science, London, UK, www.matrixscience.com) for protein identification with the following criteria: (1) species, Homo sapiens; (2) allowed one missed cleavage; (3) variable modifications, Oxidation (M), Phospho (ST) and Phospho (Y); (4) peptide tolerance, $\pm 6 \mathrm{ppm}$; (5) MS/MS tolerance, $\pm 0.6 \mathrm{Da}$; (6) peptide $+2,+3$ and +4 ; and (7) enzyme specificity, none. The results were imported into Progenesis QI LC-MS software and peptides were considered to be confidently identified when matches had a high ion score $>20$ and peptides were assigned to a protein.

\section{Ingenuity}

IPA (Ingenuity ${ }^{\circledR}$ Systems, www.ingenuity.com) was used to assess pathways of differentially regulated proteins. The accession numbers of DEPs, average normalized abundances, fold changes and $p$-values were submitted to IPA. The protein pathways and the terms were identified through IPA database search.

\section{Immunohistochemistry}

Paraffin sections of xenograft tumors were used for IHC staining of angiogenesis, EMT, CSC and glycolysis markers as well as for H\&E staining (tumor histology). All staining was performed following our previously published methods [48, 49]. Briefly, paraffin sections were de-paraffinized and rehydrated, then incubated with primary antibodies o/n at $4{ }^{\circ} \mathrm{C}$. Slides were then incubated with rabbit anti-mouse or goat anti-rabbit IgG/HRP second antibody (1:100 dilution) for $45 \mathrm{~min}$. Frozen $5 \mu \mathrm{M}$ sections of xenograft tumors were used for CD31 and CD44 staining to examine the micro-vessel density (MVD) and CSC. Sections were incubated with rat anti-mouse CD31 or mouse anti-human CD44 monoclonal antibody (MAb) (1:100 dilution) $\mathrm{o} / \mathrm{n}$ at $4{ }^{\circ} \mathrm{C}$ then incubated with rabbit anti-rat HRP or Goat anti-mouse HRP (1:100 dilution) for $45 \mathrm{~min}$ at room temperature. All sections were finally developed with 3,3' diaminobenzidine (DAB) substrate solution (Sigma-Aldrich, Pty Ltd, Castle Hills, NSW, Australia), then counterstained with hematoxylin (Thermo Fisher Pty Ltd, VIC, Australia). Control slides were treated in an identical manner, by using isotype antibodies or omitting primary antibody as a negative control.

\section{RNA extraction and $q R T-P C R$}

Approximately $1 \mathrm{mg}$ of tumors from PC-3 and PC-3RR xenografts was collected and ground in liquid nitrogen. Immediately after liquid nitrogen evaporated, the total RNA was extracted and purified using the RNeasy Plus Mini Kit (Qiagen, VIC, Australia) according to the manufacturer's instructions. The concentrations of total RNA from tissues were measured by a ND-2000 NanoDrop spectrophotometer (NanoDrop Technologies, Wilmington, DE). Two micrograms (mg) of total RNA from each sample were reverse transcribed to cDNA using the SuperScript III First-strand Synthesis System Kit (Invitrogen Pty Ltd, VIC, Australia), according to the manufacturers protocol. All mRNA expression of the LDHA and $\beta$-actin gene was assessed using qRT-PCR. A Rotor-Gene instrument (Corbett Life Science, Sydney, Australia) was used for automated qRT-PCR setup of the reactions. After three independent experiments, the REST 2009 V2.0.13 (Qiagen, VIC, Australia) software was used for calculation and analysis of LDHA gene expression.

\section{LDHA siRNA transfection}

Silencer Select LDHA siRNAs and Negative Control scramble scr-siRNA were purchased from Invitrogen (Invitrogen Australia Pty Ltd, Melbourne, VIC, Australia). Transfection was performed by incubating the cells with LDHA-siRNA or scr-siRNA and LipofectAMINE 2000 at $37^{\circ} \mathrm{C}$ for $1-7$ days, following the manufacturer's protocol. For all functional studies, LDHA-siRNA was used for 4 days to achieve the best KD effect and maintain a healthy status of the cells.

\section{Cytotoxicity of FX-11}

FX-11 (a LDHA inhibitor) was purchased from Merck Millipore (VIC, Australia) and dissolved in DMSO. Cytotoxicity of FX-11 was evaluated on PC-3RR cells using an MTT assay following a published method [48]. Briefly, 2000 cells were seeded in 96-well plates incubated in culture media for $24 \mathrm{~h}$. Cells were then treated with a range of concentrations of FX-11 (0-1 mM) or the same volume of DMSO as the vehicle control in fresh media for $48 \mathrm{~h}$. The absorbance (OD) was read at $560 \mathrm{~nm}$ on a BIOTEC micro-plate reader (BIO-RAD, Hercules, CA, USA). The $\mathrm{IC}_{20}$ value ( $20 \%$ inhibitory concentration) of FX-11 was calculated and chosen for the following experiments.

\section{Colony formation assay}

PC-3RR cells with different treatments including scr-siRNA control, LDHA-siRNA, DMSO vehicle control and FX-11 were seeded for a clonogenic survival assay 
following exposure to different dose of radiations 0,2 , 4, 6, and 8 Gy. Different numbers of cells were seeded in 6 well plates in triplicates: 500 cells for 0 Gy, 1000 cells for $2 \mathrm{~Gy}, 2000$ cells for $4 \mathrm{~Gy}, 4000$ cells for $6 \mathrm{~Gy}$, and 8000 cells for $8 \mathrm{~Gy}$. After irradiation, the cells were cultured for 14 days and the number of surviving colonies (defined as a colony with $>50$ cells) were counted. Data from radiation-treated cells were normalized against the untreated cells (scored as 100\% colony forming ability). Plating efficiencies and survival fractions were calculated to obtain survival parameters and plot cell survival curves.

\section{ROS assay}

Intracellular ROS was measured by flow cytometry. The semi-confluent cells $\left(0.5 \sim 1 \times 10^{6}\right)$ in $25 \mathrm{~cm}^{2}$ flasks were treated with scr-siRNA, LDHA-siRNA, DMOS vehicle and FX-11, after 90 hours of scr-siRNA and LDHAsiRNA treatments or 42 hours of DMSO vehicle and FX11 treatments, the cells were irradiated at 6 Gy. At 6 hours post RT, culture media was replaced with CellROX Green Reagent (Molecular Probes; MA USA) solution (1:1000 in plain RPMI-1640) and was incubated for 20 min. Following detachment and washing, cells were analyzed using a FACS Canto II Flow Cytometer (Becton, Dickinson and Company, BD Biosciences, San Jose, USA).

\section{Western blot}

Cultured PC-3RR cells in $25 \mathrm{~cm}^{2}$ flasks were treated with scr-siRNA, scr-siRNA+RT, LDHA-siRNA, LDHAsiRNA+RT, vehicle control, vehicle control+RT, FX-11, FX-11+RT. There was a 90 hours interval between LDHAsiRNA/scr-siRNA and RT treatments or a 42 hours interval between FX-11/vehicle control and RT treatments. At 6 hours post RT treatments, proteins were extracted. Protein expression levels were determined by Western blot analysis as described [48]. Briefly, whole cell lysates were separated by NuPAGE Novex 4-12\% Bis-Tris gel electrophoresis and then transferred to polyvinylidene difluoride membrane. After blocking non-specific sites with 5\% bovine serum albumin, the membrane was incubated with different primary antibodies (see Table 2), followed by incubation with HRP-conjugated secondary antibodies (goat antimouse or goat anti-rabbit appropriate for the host species of the primary antibody) (1:2000 dilution). Immunoreactive bands were detected using enhanced chemiluminescence (ECL) substrate (Pierce Chemical Co, Rockford, USA), and imaged using the ImageQuant LAS4000 system (GE Health care, USA). To confirm equal loading of protein lysates, membranes were re-probed using mouse anti-human $\beta$-actin antibody (1:5000 dilution), then processed as above.

\section{Immunofluorescent staining}

Immunofluorescence staining was performed as previously described [8]. Briefly, the cultured PC-3RR cells with different treatments as mentioned above in Western blotting were cytospined at room temperature and then incubated with $10 \%$ normal goat serum in TBS for $20 \mathrm{~min}$ to suppress the nonspecific binding of $\mathrm{IgG}$. The cells were then incubated with anti-caspase-3-active $(1: 500) \mathrm{o} / \mathrm{n}$ at $4{ }^{\circ} \mathrm{C}$. After rinsing in TBS, cells were incubated for $45 \mathrm{~min}$ in goat anti-rabbit Alexa Fluor-488 conjugate secondary antibodies (1:1000 dilutions) at room temperature. Propidium iodide (PI) $(0.2 \mathrm{mg} / \mathrm{L})$ was used to stain the nuclei. Negative controls were treated identically but omitted with the primary antibodies. Immunofluorescence was visualized using an FV 300/ FV500 Olympus laser scanning confocal microscope (Olympus).

\section{Detection of apoptosis using acridineorange/ ethidium bromide (AO/EB) staining}

The cultured PC-3RR cells with different treatments as mentioned above in Western blot were prepared for detection of apoptosis by $\mathrm{AO} / \mathrm{EB}$ staining using our published method [50].

\section{Statistical analysis}

ANOVA was used in progenesis QI analysis. All experiments were performed at least three times and data was presented as the mean \pm standard deviation (SD), unless otherwise indicated. Data from different groups were compared using the two-tail student's t test. All $p$ values were two-sided. $p<0.05$ was considered significant. The statistical analysis of immunostaining intensity in animal xenografts was performed as described in our previous publication [51]. All numerical statistical analyses were performed using the GraphPad Prism 6 package (GraphPad, CA, USA).

\section{ACKNOWLEDGMENTS}

This work was supported by the Macedonia Cancer Research Award (J. Hao), NHMRC Career Development Fellowship (Y. Li), Cancer Research Trust Fund at Cancer Care Centre.

\section{CONFLICTS OF INTEREST}

No conflicts of interest are disclosed by the authors.

\section{REFERENCES}

1. Khuntia D, Reddy CA, Mahadevan A, Klein EA and Kupelian PA. Recurrence-free survival rates after externalbeam radiotherapy for patients with clinical T1-T3 prostate carcinoma in the prostate-specific antigen era: what should we expect? Cancer. 2004; 100:1283-1292. 
2. West CM, Davidson SE, Elyan SA, Swindell R, Roberts SA, Orton CJ, Coyle CA, Valentine H, Wilks DP, Hunter RD and Hendry JH. The intrinsic radiosensitivity of normal and tumour cells. Int J Radiat Biol. 1998; 73:409-413.

3. Balmukhanov SB, Yefimov ML and Kleinbock TS. Acquired radioresistance of tumour cells. Nature. 1967; 216:709-711.

4. Wei K, Kodym R and Jin C. Radioresistant cell strain of human fibrosarcoma cells obtained after long-term exposure to X-rays. Radiat Environ Biophys. 1998; 37:133-137.

5. Frese KK and Tuveson DA. Maximizing mouse cancer models. Nat Rev Cancer. 2007; 7:645-658.

6. Whiteaker JR, Zhang H, Zhao L, Wang P, Kelly-Spratt KS, Ivey RG, Piening BD, Feng LC, Kasarda E, Gurley KE, Eng JK, Chodosh LA, Kemp CJ, McIntosh MW and Paulovich AG. Integrated pipeline for mass spectrometry-based discovery and confirmation of biomarkers demonstrated in a mouse model of breast cancer. J Proteome Res. 2007; 6:3962-3975.

7. Kalin TV, Ustiyan V and Kalinichenko VV. Multiple faces of FoxM1 transcription factor: lessons from transgenic mouse models. Cell Cycle. 2011; 10:396-405.

8. Chang L, Graham PH, Hao J, Ni J, Bucci J, Cozzi PJ, Kearsley JH and Li Y. Acquisition of epithelialmesenchymal transition and cancer stem cell phenotypes is associated with activation of the PI3K/Akt/mTOR pathway in prostate cancer radioresistance. Cell Death Dis. 2013; 4:e875.

9. Skvortsova I, Debbage P, Kumar V and Skvortsov S. Radiation resistance: Cancer stem cells (CSCs) and their enigmatic prosurvival signaling. Semin Cancer Biol. 2015; 35:39-44.

10. Harada H, Kizaka-Kondoh S, Li G, Itasaka S, Shibuya $\mathrm{K}$, Inoue $\mathrm{M}$ and Hiraoka M. Significance of HIF-1-active cells in angiogenesis and radioresistance. Oncogene. 2007; 26:7508-7516.

11. Sattler UG and Mueller-Klieser W. The anti-oxidant capacity of tumour glycolysis. Int J Radiat Biol. 2009; 85:963-971.

12. Meng MB, Wang HH, Guo WH, Wu ZQ, Zeng XL, Zaorsky NG, Shi HS, Qian D, Niu ZM, Jiang B, Zhao LJ, Yuan ZY and Wang P. Targeting pyruvate kinase M2 contributes to radiosensitivity of non-small cell lung cancer cells in vitro and in vivo. Cancer letters. 2015; 356:985-993.

13. Alvero AB, Montagna MK, Sumi NJ, Joo WD, Graham E and Mor G. Multiple blocks in the engagement of oxidative phosphorylation in putative ovarian cancer stem cells: implication for maintenance therapy with glycolysis inhibitors. Oncotarget. 2014; 5:8703-8715.doi: 10.18632/oncotarget.2367

14. Chen HC, Lee JT, Shih CP, Chao TT, Sytwu HK, Li SL, Fang MC, Chen HK, Lin YC, Kuo CY and Wang CH. Hypoxia Induces a Metabolic Shift and Enhances the Stemness and Expansion of Cochlear Spiral Ganglion Stem/ Progenitor Cells. Biomed Res Int. 2015; 2015:359537.
15. Hamabe A, Konno M, Tanuma N, Shima H, Tsunekuni K, Kawamoto K, Nishida N, Koseki J, Mimori K, Gotoh N, Yamamoto H, Doki Y, Mori M and Ishii H. Role of pyruvate kinase M2 in transcriptional regulation leading to epithelialmesenchymal transition. Proc Natl Acad Sci U S A. 2014; 111:15526-15531.

16. Kondaveeti Y, Guttilla Reed IK and White BA. Epithelialmesenchymal transition induces similar metabolic alterations in two independent breast cancer cell lines. Cancer lett. 2015; 364:44-58.

17. Li L, Zhang Y, Qiao J, Yang JJ and Liu ZR. Pyruvate kinase M2 in blood circulation facilitates tumor growth by promoting angiogenesis. J Biol Chem. 2014; 289:25812-25821.

18. Girgis H, Masui O, White NM, Scorilas A, Rotondo F, Seivwright A, Gabril M, Filter ER, Girgis AH, Bjarnason GA, Jewett MA, Evans A, Al-Haddad S, Siu KM and Yousef GM. Lactate dehydrogenase $\mathrm{A}$ is a potential prognostic marker in clear cell renal cell carcinoma. Mol Cancer. 2014; 13:101.

19. Koukourakis MI, Kontomanolis E, Giatromanolaki A, Sivridis E and Liberis V. Serum and tissue LDH levels in patients with breast/gynaecological cancer and benign diseases. Gynecol Obstet Invest. 2009; 67:162-168.

20. Miao P, Sheng S, Sun X, Liu J and Huang G. Lactate dehydrogenase A in cancer: a promising target for diagnosis and therapy. IUBMB Life. 2013; 65:904-910.

21. Rong Y, Wu W, Ni X, Kuang T, Jin D, Wang D and Lou $\mathrm{W}$. Lactate dehydrogenase $\mathrm{A}$ is overexpressed in pancreatic cancer and promotes the growth of pancreatic cancer cells. Tumour Biol. 2013; 34:1523-1530.

22. Koukourakis MI, Giatromanolaki A, Winter S, Leek R, Sivridis E and Harris AL. Lactate dehydrogenase 5 expression in squamous cell head and neck cancer relates to prognosis following radical or postoperative radiotherapy. Oncology. 2009; 77:285-292.

23. Sattler UG, Meyer SS, Quennet V, Hoerner C, Knoerzer H, Fabian C, Yaromina A, Zips D, Walenta S, Baumann M and Mueller-Klieser W. Glycolytic metabolism and tumour response to fractionated irradiation. Radiother Oncol. 2010; 94:102-109.

24. Yamada Y, Nakamura K, Aoki S, Tobiume M, Zennami K, Kato Y, Nishikawa G, Yoshizawa T, Itoh Y, Nakaoka A, Yoshida E, Uchiyama $\mathrm{T}$ and Honda N. Lactate dehydrogenase, Gleason score and HER-2 overexpression are significant prognostic factors for M1b prostate cancer. Oncol Rep. 2011; 25:937-944.

25. Koukourakis MI, Giatromanolaki A, Panteliadou M, Pouliliou SE, Chondrou PS, Mavropoulou S and Sivridis E. Lactate dehydrogenase 5 isoenzyme overexpression defines resistance of prostate cancer to radiotherapy. Br J Cancer. 2014; 110:2217-2223.

26. Chen N, Wu L, Yuan H and Wang J. ROS/Autophagy/Nrf2 Pathway Mediated Low-Dose Radiation Induced RadioResistance in Human Lung Adenocarcinoma A549 Cell. Int J Biol Sci. 2015; 11:833-844. 
27. Brand KA and Hermfisse U. Aerobic glycolysis by proliferating cells: a protective strategy against reactive oxygen species. Faseb j. 1997; 11:388-395.

28. Arseneault R, Chien A, Newington JT, Rappon T, Harris R and Cumming RC. Attenuation of LDHA expression in cancer cells leads to redox-dependent alterations in cytoskeletal structure and cell migration. Cancer lett. 2013; 338:255-266.

29. Le A, Cooper CR, Gouw AM, Dinavahi R, Maitra A, Deck LM, Royer RE, Vander Jagt DL, Semenza GL and Dang $\mathrm{CV}$. Inhibition of lactate dehydrogenase A induces oxidative stress and inhibits tumor progression. Proc Natl Acad Sci U S A. 2010; 107:2037-2042.

30. Shintani Y, Okimura A, Sato K, Nakagiri T, Kadota Y, Inoue M, Sawabata N, Minami M, Ikeda N, Kawahara K, Matsumoto T, Matsuura N, Ohta M and Okumura M. Epithelial to mesenchymal transition is a determinant of sensitivity to chemoradiotherapy in non-small cell lung cancer. Ann Thorac Surg. 2011; 92:1794-1804.

31. Kang J, Kim E, Kim W, Seong KM, Youn H, Kim JW, Kim $\mathrm{J}$ and Youn B. Rhamnetin and cirsiliol induce radiosensitization and inhibition of epithelial-mesenchymal transition (EMT) by miR-34a-mediated suppression of Notch-1 expression in non-small cell lung cancer cell lines. J Biol Chem. 2013; 288:27343-27357.

32. Chua YL, Dufour E, Dassa EP, Rustin P, Jacobs HT, Taylor CT and Hagen T. Stabilization of hypoxia-inducible factor-1alpha protein in hypoxia occurs independently of mitochondrial reactive oxygen species production. J Biol Chem. 2010; 285:31277-31284.

33. Tsui KH, Chung LC, Wang SW, Feng TH, Chang PL and Juang HH. Hypoxia upregulates the gene expression of mitochondrial aconitase in prostate carcinoma cells. J Mol Endocrinol. 2013; 51:131-141.

34. Semenza GL. Oxygen-dependent regulation of mitochondrial respiration by hypoxia-inducible factor 1 . Biochem J. 2007; 405:1-9.

35. Maiso P, Huynh D, Moschetta M, Sacco A, Aljawai Y, Mishima Y, Asara JM, Roccaro AM, Kimmelman AC and Ghobrial IM. Metabolic signature identifies novel targets for drug resistance in Multiple Myeloma. Cancer Res. 2015; 75:2071-2082.

36. Bertout JA, Patel SA and Simon MC. The impact of O2 availability on human cancer. Nat Rev Cancer. 2008; 8:967-975.

37. Pajonk F, Vlashi E and McBride WH. Radiation resistance of cancer stem cells: the 4 R's of radiobiology revisited. Stem Cells. 2010; 28:639-648.

38. Rogakou EP, Pilch DR, Orr AH, Ivanova VS and Bonner WM. DNA double-stranded breaks induce histone H2AX phosphorylation on serine 139. J Biol Chem. 1998; 273:5858-5868.

39. Xiao W, Graham PH, Hao J, Chang L, Ni J, Power CA, Dong Q, Kearsley JH and Li Y. Combination therapy with the histone deacetylase inhibitor LBH589 and radiation is an effective regimen for prostate cancer cells. PLoS One. 2013; 8:e74253.

40. Zhou S, Zhao L, Kuang M, Zhang B, Liang Z, Yi T, Wei $\mathrm{Y}$ and Zhao X. Autophagy in tumorigenesis and cancer therapy: Dr. Jekyll or Mr. Hyde? Cancer lett. 2012; 323:115-127.

41. Martinez-Outschoorn UE, Prisco M, Ertel A, Tsirigos A, Lin Z, Pavlides S, Wang C, Flomenberg N, Knudsen ES, Howell A, Pestell RG, Sotgia F and Lisanti MP. Ketones and lactate increase cancer cell "stemness," driving recurrence, metastasis and poor clinical outcome in breast cancer: achieving personalized medicine via MetaboloGenomics. Cell Cycle. 2011; 10:1271-1286.

42. Li $\mathrm{X}, \mathrm{Xu} \mathrm{HL}$, Liu YX, An N, Zhao $\mathrm{S}$ and Bao JK. Autophagy modulation as a target for anticancer drug discovery. Acta Pharmacol Sin. 2013; 34:612-624.

43. Li Y, Song E, Abbas Rizvi SM, Power CA, Beretov J, Raja C, Cozzi PJ, Morgenstern A, Apostolidis C, Allen BJ and Russell PJ. Inhibition of micrometastatic prostate cancer cell spread in animal models by 213Bilabeled multiple targeted alpha radioimmunoconjugates. Clin Cancer Res. $2009 ; 15: 865-875$.

44. Gleave M, Hsieh JT, Gao CA, von Eschenbach AC and Chung LW. Acceleration of human prostate cancer growth in vivo by factors produced by prostate and bone fibroblasts. Cancer Res. 1991; 51:3753-3761.

45. Duan X, Young R, Straubinger RM, Page B, Cao J, Wang H, Yu H, Canty JM and Qu J. A straightforward and highly efficient precipitation/on-pellet digestion procedure coupled with a long gradient nano-LC separation and Orbitrap mass spectrometry for label-free expression profiling of the swine heart mitochondrial proteome. J Proteome Res. 2009; 8:2838-2850.

46. Cruciani F, Wasinger V, Turroni S, Calanni F, Donders G, Brigidi $\mathrm{P}$ and Vitali B. Proteome profiles of vaginal fluids from women affected by bacterial vaginosis and healthy controls: outcomes of rifaximin treatment. Journal of Antimicrobial Chemotherapy. 2013; 68:2648-2659.

47. Karp NA, McCormick PS, Russell MR and Lilley KS. Experimental and statistical considerations to avoid false conclusions in proteomics studies using differential in-gel electrophoresis. Mol Cell Proteomics. 2007; 6:1354-1364.

48. Hao J, Madigan MC, Khatri A, Power CA, Hung TT, Beretov J, Chang L, Xiao W, Cozzi PJ, Graham PH, Kearsley JH and $\mathrm{Li} \mathrm{Y}$. In vitro and in vivo prostate cancer metastasis and chemoresistance can be modulated by expression of either CD44 or CD147. PLoS One. 2012; 7:e40716.

49. Wang L, Chen H, Pourgholami MH, Beretov J, Hao J, Chao H, Perkins AC, Kearsley JH and Li Y. Anti-MUC1 monoclonal antibody (C595) and docetaxel markedly reduce tumor burden and ascites, and prolong survival in an in vivo ovarian cancer model. PLoS One. 2011; 6:e2 4405 . 
50. Li Y, Wang J, Rizvi SM, Jager MJ, Conway RM, Billson FA, Allen BJ and Madigan MC. In vitro targeting of NG2 antigen by 213Bi-9.2.27 alpha-immunoconjugate induces cytotoxicity in human uveal melanoma cells. Invest Ophthalmol Vis Sci. 2005; 46:4365-4371.

51. Wang L, Chen H, Pourgholami MH, Beretov J, Hao J, Chao H, Perkins AC, Kearsley JH and Li Y. Anti-MUC1 monoclonal antibody (C595) and docetaxel markedly reduce tumor burden and ascites, and prolong survival in an in vivo ovarian cancer model. PLoS ONE. 2011;6:e24405. 